\section{Hypopharyngeal hirudiniasis presenting as hematemesis}

Leeches belong to the Annelida division, Clitellata class, Hirudinea subclass. Common species of leeches that infest humans are Dinobdella ferox, Hirudinea granulosa, and Hirundinea viridis [1].

A 72-year-old man, a cattle breeder, presented to the emergency room with hematemesis of 10 days' duration. He reported having drunk water from an open trough. He was conscious, and the physical examination findings were normal. He had a history of smoking 50 packs per year, but no co-morbidities or alcohol use. The hematology values at presentation were as follows: white cell count, $10500 / \mathrm{mm}^{3}$; hemoglobin, $11.7 \mathrm{~g} / \mathrm{dL}$; mean corpuscular volume, $85 / \mathrm{\mu m}^{3}$; platelet count, $357000 / \mathrm{mm}^{3}$. The next morning, the blood values were similar, without any significant changes. Endoscopic examination revealed several crater-type lesions that were slightly elevated from the mucosa, some of which were slowly bleeding. The lesions were located in the posterior wall of the oropharynx, root of the tongue, some parts of the esophagus, and the cardia region of the stomach. A careful endoscopic examination of the hypopharyngeal area revealed a live mobile organism, which was identified as a leech ( Fig. 1, Fig.2, Fig.3). It was carefully removed with a surgical clamp. Follow-up blood tests revealed no significant changes in the hemoglobin values.

Leeches are known to adhere to various regions of the body. They may cause anemia and various symptoms, such as hemoptysis, epistaxis, nasal congestion, stridor, headache, hematemesis, difficulty swallowing, and vaginal bleeding. When the trachea and bronchi are affected by bleeding, asphyxia and death can occur [2]. Death as a result of profuse bleeding after the removal of leeches has been recorded [3].

If a leech is located in the nasopharynx and can be seen with the naked eye, it may be easier and preferable to have an otolaryngologist remove it with a surgical clamp [4]. The consumption of water from unsafe sources can still be risky in some rural areas. When patients in rural areas present with upper gastrointestinal bleeding of unknown cause, the possibility of leech infestation should not be overlooked.

\section{Endoscopy_UCTN_Code_CCL_1AB_2AB}

\section{Competing interests: None}

\section{Haluk Tarik Kani ${ }^{1}$, Yucel Aydin², Nezih Yalcin ${ }^{1}$, Mustafa Kaymakci ${ }^{3}$, Hakan Akin²}

${ }^{1}$ Department of Internal Medicine, Marmara University, Istanbul, Turkey

${ }^{2}$ Departments of Internal Medicine and Gastroenterology, Marmara University, Istanbul, Turkey

${ }^{3}$ Department of Ear, Nose, and Throat, Balikesir University, Balikesir, Turkey

\section{References}

1 Sağlam N. Protection and sustainability, exportation of some species of Medicinal Leeches (Hirudo medicinalis L. 1758 and Hirudo verbana Carena, 1820). Journal of Fisheries Sciences 2011. doi: 10.3153/ jfscom.2011001

2 Uzun B, Korucuk E, Sezak NB et al. [A case of leech infestation mimicking upper respiratory tract infection]. Turkiye Parazitol Derg 2011; 35: 169-171

3 Kavakli HS, Tannverdi F. Bilateral hemarthrosis due to hirudotherapy: case report. Journal of Academic Emergency Medicine Case Reports 2010; 1: 20-22

4 Çoban Ş, Tutal E, Alpay D et al. An unexpected cause of severe anemia in an adult patient: a pharyngeal leech (with video). Gastrointest Endosc 2011; 73: 360-361

\section{Bibliography}

Dol http://dx.doi.org/

10.1055/s-0034-1377954

Endoscopy 2014; 46: E550

(c) Georg Thieme Verlag KG

Stuttgart · New York

ISSN 0013-726X

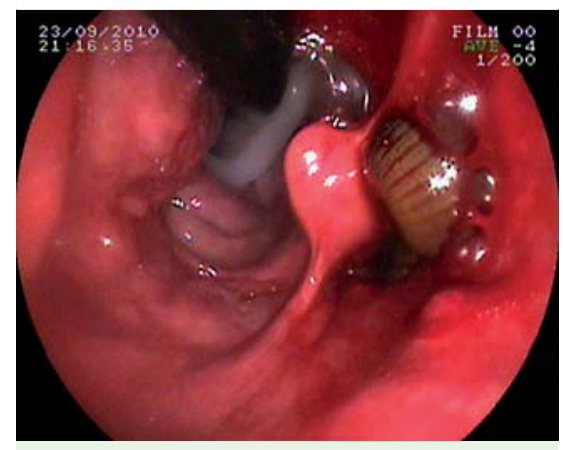

Fig. 1 Hypopharyngeal hirudiniasis. View through the retroflexed scope shows the leech, uvula, and a slowly bleeding crater-type lesion.

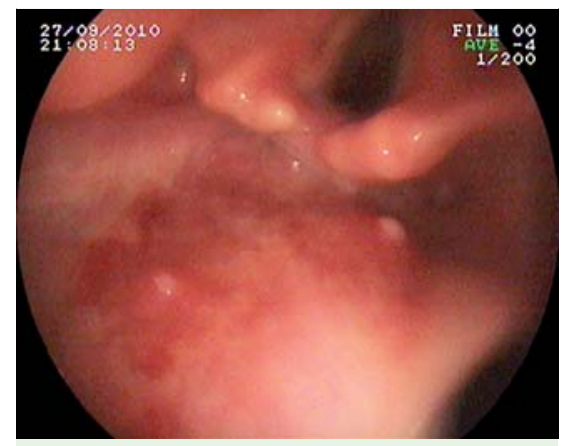

Fig. 2 Root of the tongue and vocal cords. Two bleeding crater-type lesions are seen.

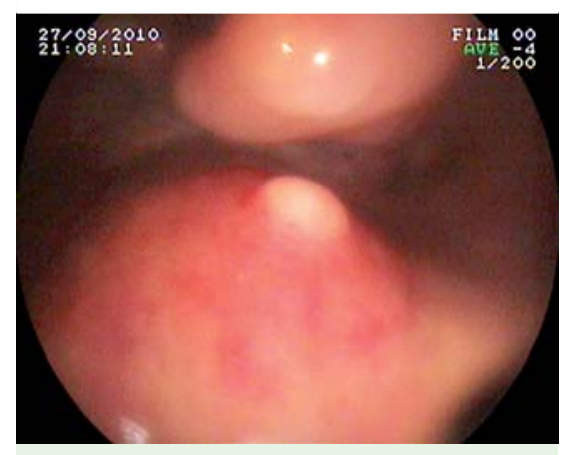

Fig.3 Closer view of the crater-type lesion and root of the tongue.

\section{Corresponding author}

\section{Hakan Akin, MD}

Department of Internal Medicine and Gastroenterology

Marmara University

Basibuyuk Kampusu Maltepe

Istanbul 34800

Turkey

Fax: +90 2164214379

drhakanakin@gmail.com

hakan.akin@marmara.edu.tr 